\title{
Knowledge, perceptions and practices towards medical ethics among physician residents of University of Alexandria hospitals, Egypt
}

\author{
A.M. Mohamed, ${ }^{7}$ M.A. Ghanem ${ }^{2}$ and A.A. Kassem ${ }^{3}$
}

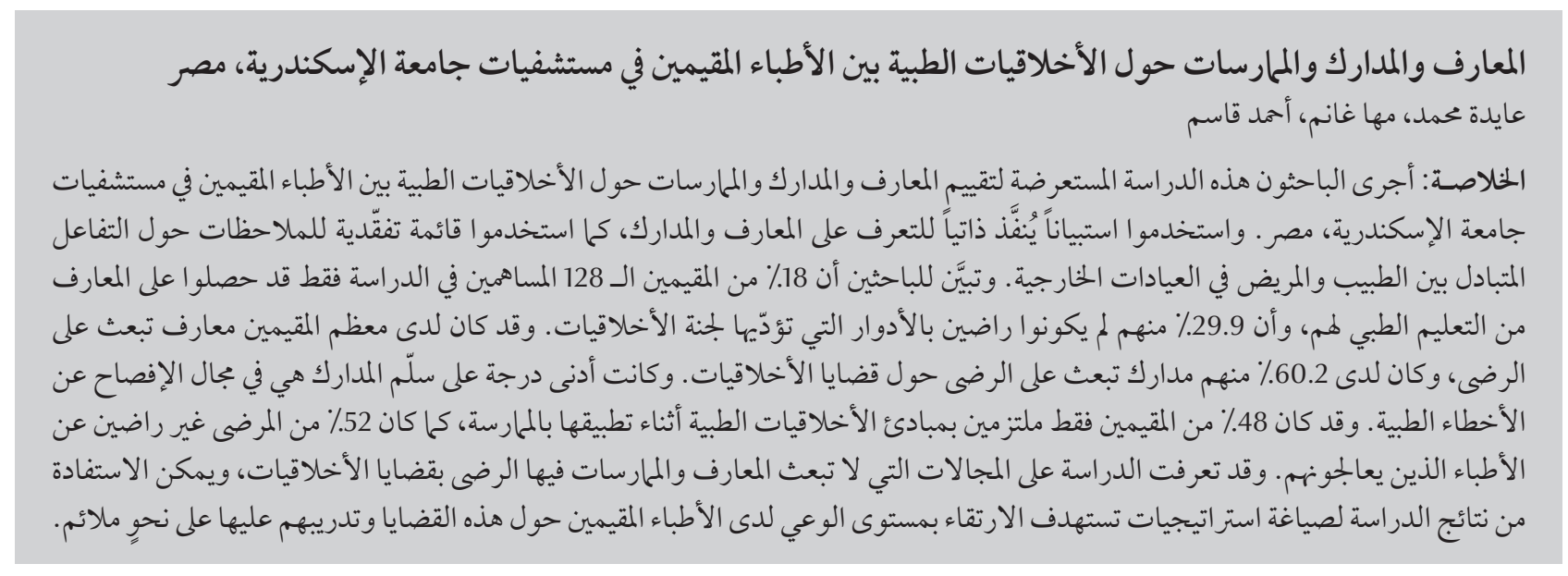

ABSTRACT This cross-sectional study was conducted to assess the knowledge, perceptions and practices towards medical ethics of physician residents at university hospitals in Alexandria, Egypt. A self-administered structured questionnaire was used for knowledge and perceptions and a checklist for observations of doctor-patient interactions in the outpatient setting. Only $18.0 \%$ of the 128 participating residents had obtained their knowledge from their medical education and $29.9 \%$ were dissatisfied with the roles played by the ethics committee. Most of the residents had satisfactory knowledge and $60.2 \%$ had satisfactory perceptions regarding ethical issues. The lowest perception score was in the domain of disclosing medical errors. Only $48.0 \%$ of the residents were compliant with the principles of medical ethics in practice and $52.0 \%$ of patients were dissatisfied with their treating physicians. The study identified areas of unsatisfactory knowledge and practices towards ethical issues so as to devise means to sensitize residents to these issues and train them appropriately.

\section{Connaissances, perceptions et pratiques en matière d'éthique médicale des internes des centres hospitaliers universitaires d'Alexandrie (Égypte)}

RÉSUMÉ La présente étude transversale a été menée afin d'évaluer les connaissances, les perceptions et les pratiques en matière d'éthique médicale des internes exerçant dans des centres hospitaliers universitaires d'Alexandrie (Égypte). Un questionnaire autoadministré et structuré a été utilisé pour évaluer les connaissances et les perceptions des répondants. Une liste de contrôle des observations réalisées à partir des interactions entre le médecin et le patient en consultation externe a aussi été utilisée. Seuls 18,0 \% des 128 internes participant avaient acquis leurs connaissances pendant leurs études de médecine et 29,9 \% n'étaient pas satisfaits du rôle joué par le comité d'éthique. La plupart des internes avaient des connaissances satisfaisantes et $60,2 \%$ une perception satisfaisante des questions éthiques. Le score le plus faible a été obtenu pour la perception de la divulgation des erreurs médicales. Seuls $48,0 \%$ des internes respectaient les principes de l'éthique médicale dans la pratique, alors que $52,0 \%$ des patients étaient mécontents de leur médecin traitant. L'étude a permis d'identifier des domaines où les connaissances et les pratiques en matière d'éthique étaitent insuffisantes. Les résultats pourront être exploités pour concevoir des moyens permettant de sensibiliser les internes à ces questions et de les former convenablement. 


\section{Introduction}

Medical ethics has been included in the training curriculum of health professionals in many countries and there has been a growth in the number of ethics specialists and ethics committees. Yet complaints from the public appear to be proliferating [1]. This may be a reflection of an increased public awareness as well as poor practices within the health care sector. Traditional medical training offers little help in resolving the ethical dilemmas encountered by health care professionals. It has been argued that very few physicians are exposed to training in this important area of medical practice, yet on qualifying health care professionals are expected to know about ethical practice when applying their skills [1].

In the faculty of medicine in Alexandria, Egypt, formal teaching of medical ethics at the undergraduate and postgraduate levels is done as part of medical jurisprudence. One problem is that medical students do not have much interest in learning about medical ethics as they consider other subjects to be more important for qualifying for examinations. Moreover, professional conduct and etiquette are learnt by observation rather than through theory. Yet students may not find role models for ethical practice among their teachers. Senior doctors' practices influence the behaviour and attitudes of junior doctors. The teaching environment and methods are also not favourable for the teaching of ethics [2].

To our knowledge, there have been no previous surveys of postgraduate clinical trainees affiliated to the University of Alexandria faculty of medicine. This study was conducted to reveal knowledge and perception of medical ethics among physician residents in University of Alexandria hospitals and to assess the degree to which they adhere to ethical practices during outpatient consultations.

\section{Methods}

\section{Setting and sample}

A descriptive cross-sectional survey was conducted at the 3 university hospitals of Alexandria from August 2009 to September 2010. All physician residents of the faculty of medicine at University of Alexandria, working in 16 clinical departments, were invited to participate in this survey $(n=255$, according to the hospital information system, 2008). A total of 128 completed and submitted the questionnaires. Observations were done on 100 residents (28 refused to be observed).

A sample of patients attending 10 of the 16 outpatient clinics were invited to participate in the survey. A multistage random sampling technique was used to select patients. With the assumption that patients' perception of good ethical practices were $50 \%$ and using significance level of $0.05 \%$ a sample size of 100 patients was estimated. The outpatient registration record for such clinics was used to enrol patients for the study using systematic random sampling. All patients agreed to participate in the study.

\section{Data collection}

\section{Tools}

Three tools were developed:

- An anonymous self-administered questionnaire was devised for this study based on a review of the literature. It collected data about the demographic characteristics of physicians (sex, occupational category and postgraduate year), frequency of ethical problems encountered in practice, sources of knowledge about medical ethics, who they preferred to consult about ethical problems when these arise and knowledge of ethics committees and their roles. Another section included a range of statements designed (after a thorough review of the literature) to identify respondents' knowledge about medical ethics, perceptions towards physician-patient ethics, physician-colleague relationships and disclosure of medical errors.

- An observation checklist assessed how far the physicians adhered to specified principles of medical ethics: informed consent, privacy, confidentiality and collaboration of patients in the process of decision-making for treatment.

- An interview tool obtained information about the demographic characteristics of patients and their satisfaction with adherence of physicians to the principles of medical ethics: physicians' practices of informed consent, privacy and confidentiality and the way that physicians discussed treatment with them.

All these tools were pilot-tested on 15 residents and 15 patients. The main obstacle encountered was the poor cooperation of residents in returning the questionnaire. This was due to high workload and shift work patterns. The response rate was $77.6 \%$ and this did not differ significantly by department of affiliation. A random subset of 30 residents also completed the survey to assess the reliability of the research tools. Intra-class correlation coefficients were used to compute internal reliability estimates. Evaluations of reliability of tools were done using Cronbach alpha.

\section{Scoring}

Variables were processed as following:

- The knowledge about medical ethics scale comprised 13 statements ( scored $1=$ know and $0=$ don't know; negative questions were reverse scored $)(\alpha=0.86)$. The total knowledge score was calculated as a percentage of the maximum possible score.

- The perceptions towards physician-patients ethics scale comprised 13 statements concerning ethical conduct, autonomy, paternalism, confidentiality, informing patients about wrong-doing and informing relatives about the patient's condition, informed consent, treating 
non-compliant or violent patients, religious beliefs influencing treatment and abortion and euthanasia. The perceptions towards disclosing medical errors scale comprised 4 statements. The perception scale of physician-colleague relationships comprised 6 statements (all scored as $1=$ agree and $0=$ disagree). Composite perception scores was calculated by summing the 23 perception statements scores, negative questions were reverse scored $(\alpha=0.90)$. The total perception score was calculated as a percentage of the maximum possible score.

- The compliance scale comprised 15 statements (scored $1=$ done and $0=$ not done) $(\alpha=0.82)$. The total compliance score was calculated as a percentage of the maximum possible score.

- Patients'satisfaction scale comprised 9 statements ( scored $1=$ satisfied and $0=$ dissatisfied $)(\alpha=0.83)$. The total satisfaction score was calculated as a percentage of the maximum possible score.

Satisfactory knowledge, perception and compliance of residents to ethical practices and adequate patients' satisfaction were defined as percentage scores above the median percentage score.

\section{Ethical considerations}

The ethics committee of the faculty of medicine approved the study. Informed consent was taken from physicians and patients before starting data collection, after a full explanation of the purpose and aims of the study. Questionnaires were distributed by the investigator herself with a covering letter indicating the purpose of the study, confidentiality procedures and faculty review approval. Informed consent was taken from physicians before starting collecting data, after a full explanation of the purpose and aims of the study. Participants' anonymity was preserved. Data about responses and views of physicians and patients as well as the performance of each resident remained undisclosed by the researcher.

\section{Data processing and analysis}

After data collection, the raw data was coded and scored and a coding instruction manual was prepared. Data were fed to the computer and statistical analysis was performed using SPSS, version 18.0. The significance of the results was judged at the $5 \%$ level of significance.

\section{Results}

\section{Physicians' characteristics}

The characteristics of the 128 resident physicians who completed the questionnaires have been described in a previous paper [3]. Two-fifths of residents $(40.6 \%)$ had learned about medical ethics from their own experience at work, $27.3 \%$ had read about it and $18.0 \%$ had their knowledge from their medical education; only $14.1 \%$ gained their knowledge from exposure to a training course on the subject. Of the total residents approached, 98.0\% admitted facing ethical problems and the rest $(2.0 \%)$ denied it. More than one-third $(37.0 \%)$ stated that they faced them daily. One-third (33.0\%) of physicians consulted their immediate supervisor when they encountered an ethical problem, $24.0 \%$ went to the ethics committee, $19.0 \%$ asked advice from a colleague and the rest either consulted a professor $(15.0 \%)$ or the head of the department (9.0\%).

\section{Physicians' knowledge about ethics committees}

Only 4 physicians (3.1\%) did not know about the existence of the ethics committee in the faculty of medicine. All residents felt that among the roles of this committee was to approve and guide research. Manyresidents (72.6\%) claimed that it had a role in teaching medical ethics and $8.1 \%$ that it conducted medical ethics conferences. Asked about its role, $58.9 \%$ thought it was to ensure standard ethical practices of health care personnel, $24.2 \%$ to advise health care personnel about ethical problems and $12.1 \%$ to advise administrators. A few residents stated that the committee resolved conflicts between professionals (2.4\%) and between professionals and patients' relatives (1.6\%). Apart of those who denied its existence (3.1\%), 29.9\% were dissatisfied with its role.

\section{Physicians' knowledge about medical ethics and rights of patients}

All residents except 1 believed that medical ethics was an essential subject for physicians and $86.7 \%$ were able to define it. A majority (89.8\%) agreed that rapport can be established between physician and patient in medical practice. Most residents (91.4\%) could mention at least 1 of the 4 patients' rights: privacy (89.8\%), obtaining an informed consent $(87.5 \%)$, veracity $(85.9 \%)$ and beneficence ( $84.4 \%)$. More than two-thirds of them (68.7\%) stated non-maleficence and less than two-thirds mentioned autonomy as a right. Justice and confidentiality were mentioned each by $59.4 \%$.

Less than half the physicians (45.3\%) were of the opinion that disclosure of medical reports is a good idea. The majority (97.7\%) agreed that the patient has the right for a second medical opinion and $74.0 \%$ felt it is good for to patients learn about their own disorders through the Internet and/or books.

The majority of residents (96.9\%) agreed that palliative care is good and that medical treatment should rely heavily on drugs (88.3\%). When asked whether as a routine physicians should describe and/or explain aspects of therapy there was agreement about explaining methods of drug use (99.2\%) and effects of the drug on the patient's illness (93.0\%), while fewer physicians would explain side-effects $(79.7 \%)$ or names of drugs (52.3\%) (Table 1).

The overall knowledge score ranged from $30.7 \%-92.3 \%$ with a median and 


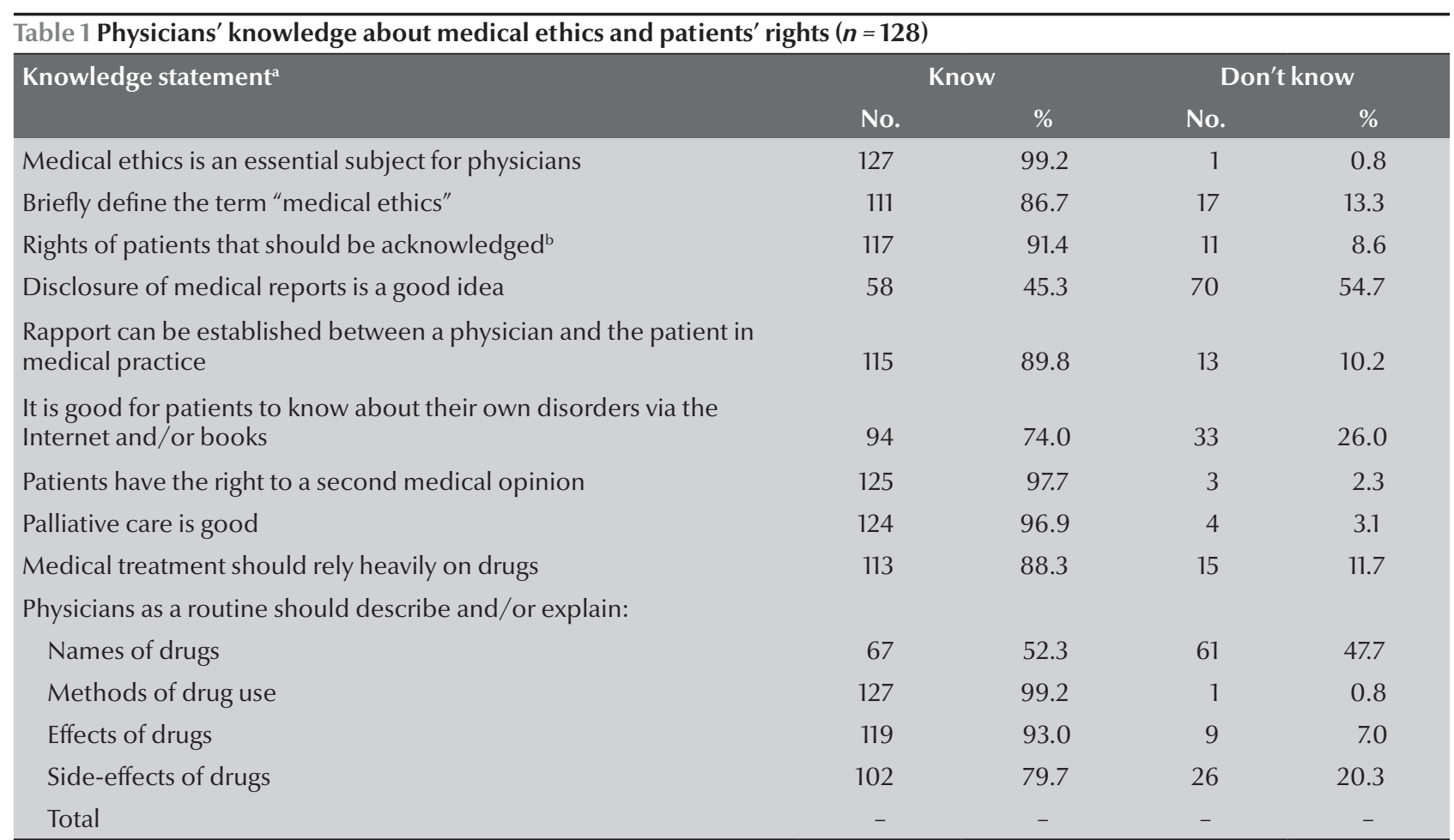

The median (interquartile range) was $80.8 \%(9.8)$.

${ }^{a}$ Statements are mutually exclusive; ${ }^{b}$ Resident was considered knowledgeable if he/she mentioned at least 4 (out of 8 ) of patient' rights: privacy, informed consent, veracity, beneficence, non-maleficience, autonomy, justice and confidentiality.

interquartile range of $80.8 \%$ (IQR 9.8\%). Over two-thirds of the residents (69.5\%) had satisfactory knowledge (total knowledge scores greater than median score). No significant knowledge differences were noted between residents by sex $(P=0.729)$, department affiliation $(P=0.258)$ or postgraduate year $(P=0.253)$ (data not shown).

\section{Physicians' perceptions about different domains of medical ethics}

The majority of residents disagreed with several statements about the physician-patient relationship: avoiding legal action (95.3\%), inability to apply it in modern care (90.6\%), assisting patients who wished to die (97.7\%), refusing to treat violent patients (88.3\%) and refusing abortions (85.2\%). The majority of physicians (96.1\%) however, agreed that children should never be treated without the consent of their parents/guardians except in an emergency and that patients should always be told if something is wrong (83.6\%). Physicians mostly agreed that confidential information can only be disclosed if the patient gives explicit consent or if expressly provided for in the law (77.3\%) but fewer agreed to tell close relatives about a patient's condition $(50.0 \%)$ or that patients should be told to find another doctor if they are refused treatment due to beliefs (60.2\%) (Table 2).

When asked about the disclosure of medical errors $32.0 \%$ would only do it in cases of death or disability while $64.1 \%$ would act in cases of only minor medical harm. Fear of malpractice was the main reason for non-disclosure of medical errors $(75.0 \%)$ but $34.4 \%$ agreed that patients' forgiveness was an important motive for disclosure (Table 2).

Concerning physician-colleague relationships $70.3 \%$ agreed that physicians should treat colleagues respectfully and work cooperatively, $54.7 \%$ that they should resolve conflicts with colleagues and $48.4 \%$ that they should cooperate with others in the care of patients. All the residents condemned stealing other colleagues' patients and only $23.4 \%$ agreed that physicians should be paid to procure the referral of a patient. However, $60.9 \%$ did not approve reporting colleagues' misconduct (Table 2).

The overall total perception score was $74.8 \%$ (IQR $6.4 \%$ ) and $60.2 \%$ of residents had a satisfactory level of perception. Of the 3 domains, the highest scores were for the domain of physician-colleague relationship (62.6\% had a satisfactory level) and the lowest for disclosing medical errors (40.7\% satisfactory), while $59.6 \%$ scored satisfactory for physician-patient relationships. No significant differences were observed as regards level of perception and sex $(P=0.749)$ or department of affiliation $(P=0.295)$. However, residents enrolled in 2nd and 3rd years (70.5\% and $66.7 \%$ ) were more likely to have a satisfactory perceptions compared with those enrolled in first (41.2\%) and 4th year of postgraduate $(48.4 \%)$ (data not shown). 


\begin{tabular}{|c|c|c|c|c|c|}
\hline \multirow[t]{2}{*}{ Perception domain/perception statement } & \multicolumn{2}{|c|}{ Agree } & \multicolumn{2}{|c|}{ Disagree } & \multirow{2}{*}{$\begin{array}{c}\text { Median } \\
\text { (IQR) score } \\
\%\end{array}$} \\
\hline & No. & $\%$ & No. & $\%$ & \\
\hline Physician-patient relationship & & & & & $77.3(8.9)$ \\
\hline Ethical conduct is important only to avoid legal action & 6 & 4.7 & 122 & 95.3 & \\
\hline Patient's wishes must always be adhered to & 74 & 57.8 & 54 & 42.2 & \\
\hline $\begin{array}{l}\text { Physician should do what is best irrespective of patient's } \\
\text { opinion }\end{array}$ & 46 & 35.9 & 82 & 64.1 & \\
\hline Patient should always be told if something is wrong & 107 & 83.6 & 21 & 16.4 & \\
\hline $\begin{array}{l}\text { Confidential information can only be disclosed if the } \\
\text { patient gives explicit consent or if expressly provided for in the law }\end{array}$ & 99 & 77.3 & 29 & 22.7 & \\
\hline $\begin{array}{l}\text { Confidentiality cannot be applied in modern care and should be } \\
\text { abandoned }\end{array}$ & 12 & 9.4 & 116 & 90.6 & \\
\hline Close relatives must always be told about a patient's condition & 64 & 50.0 & 64 & 50.0 & \\
\hline $\begin{array}{l}\text { Patients need to consent only for operations but not for tests or } \\
\text { medications }\end{array}$ & 23 & 18.0 & 105 & 82.0 & \\
\hline $\begin{array}{l}\text { Children should never be treated without the consent of their } \\
\text { parents or guardians (except in an emergency) }\end{array}$ & 123 & 96.1 & 5 & 3.9 & \\
\hline $\begin{array}{l}\text { Doctors and nurses should refuse to treat patients who behave } \\
\text { violently }\end{array}$ & 15 & 11.7 & 113 & 88.3 & \\
\hline $\begin{array}{l}\text { Patients who refuse treatment due to beliefs should be } \\
\text { instructed to find another doctor }\end{array}$ & 77 & 60.2 & 51 & 39.8 & \\
\hline $\begin{array}{l}\text { Health care worker cannot refuse to do an abortion if the law } \\
\text { allows it to be performed }\end{array}$ & 19 & 14.8 & 109 & 85.2 & \\
\hline Patient who wishes to die should be assisted in doing so & 3 & 2.3 & 125 & 97.7 & \\
\hline Disclosing medical errors & & & & & $52.7(6.9)$ \\
\hline $\begin{array}{l}\text { Would disclose medical error resulting in minor medical harm } \\
\text { (prolonged treatment/discomfort or extra cost) }\end{array}$ & 82 & 64.1 & 46 & 35.9 & \\
\hline $\begin{array}{l}\text { Would disclose medical error only if it caused major harm } \\
\text { (disability or death) }\end{array}$ & 41 & 32.0 & 87 & 68.0 & \\
\hline $\begin{array}{l}\text { Fear of malpractice is an important reason why doctors do not } \\
\text { disclose medical errors }\end{array}$ & 96 & 75.0 & 32 & 25.0 & \\
\hline $\begin{array}{l}\text { Patients' forgiveness plays an important role in motivating } \\
\text { doctors to disclose medical errors }\end{array}$ & 44 & 34.4 & 84 & 65.6 & \\
\hline Physician-colleague relationship & & & & & $69.4(8.9)$ \\
\hline $\begin{array}{l}\text { Treat colleagues respectfully and work cooperatively to } \\
\text { maximize patient care }\end{array}$ & 90 & 70.3 & 38 & 29.7 & \\
\hline Pay or receive fee to procure referral of a patient to a colleague & 30 & 23.4 & 98 & 76.6 & \\
\hline Steal patients from colleagues & 0 & 0.0 & 128 & 100.0 & \\
\hline Report colleagues' misconduct & 50 & 39.1 & 78 & 60.9 & \\
\hline $\begin{array}{l}\text { Apply the main ethical principles relating to cooperation with } \\
\text { others in patient care }\end{array}$ & 62 & 48.4 & 66 & 51.6 & \\
\hline Resolve conflicts with other health care providers & 70 & 54.7 & 58 & 45.3 & \\
\hline Total & - & - & - & - & $74.8(6.4)$ \\
\hline
\end{tabular}

$I Q R=$ interquartile range.

\section{Physicians' ethical practices}

Observations of physicians' compliance with ethical practices showed that only $48.0 \%$ of residents overall were compliant with the principles of medical ethics in practice. All residents took informed consent and complied with the principle of not harming the patient), $94.0 \%$ of them showed respect towards patients' needs and $93.0 \%$ accepted the patients' request not to be examined by medical students (Table 3). Privacy during examination was ensured by $90.0 \%$; however, only $76.0 \%$ made sure 
that no third party was present. The majority of residents $(89.0 \%)$ complied with the principles of confidentiality.

The lowest median score was for patient management $[62.7 \%$ (IQR $3.2 \%)$ ]. Only $40.0 \%$ of residents informed their patients about the cost of treatment, $53.0 \%$ shared the solution of their problem with patients or fully informed them about side-effects of treatment (54.0\%); however, $98.0 \%$ fully informed their patients as regards the cause of disease. Only $62.0 \%$ of residents made a full examination to reach their diagnosis.
Significant sex differences were noted as $61.8 \%$ of woman physicians were compliant with the principles of medical ethics compared with $31.2 \%$ of men $(P=0.003)$ (data not shown). Residents in psychiatry $(80.0 \%)$ and paediatrics $(80.0 \%)$ were significantly more likely to comply with medical ethics than those in internal medicine (50.0\%), family medicine (40.0\%) or other departments (38.3\%) (P $=0.003)$. No significant differences however, were observed as regards compliance and postgraduate year $(P$ $=0.539$ ).

\section{Patients' characteristics}

Of the 100 patients approached, $22.0 \%$ were aged $<20$ years and $43.0 \%$ were $>$ 40 years, $56.0 \%$ were male, $48.0 \%$ them were currently married, $31.0 \%$ did not hold any educational certificates and $53.0 \%$ were residing in rural areas. The majority of patients were seeking curative care $(81.0 \%)$ and the rest attended for preventive or rehabilitative care.

\section{Patients' satisfaction with services and environment}

Only $48.0 \%$ of patients were satisfied with their treating physician. About

Table 3 Physicians' observed compliance to ethical practices during physician-patient interactions $(\boldsymbol{n}=100)$

$\begin{array}{llccc}\text { Compliance practice } & \text { Done } & \text { Not done } & \text { Median (IQR) } \\ \text { score } & & \text { No. } & \% & \%\end{array}$

\section{Informed consent ${ }^{a}$}

$100.0(0.0)$

Took informed consent from patient (before history-

taking, before examination or before exposing any

body part)

Patient right not to be harmed

Did not prescribed medication that was not

indicated (e.g. only for research)

Did not order investigations that were not

indicated (e.g. only for research)

\section{Respect and dignity}

Showed respect, dignity, responsiveness and attention to patient's health needs

Accepted patient's request not to be examined by medical students

\section{Privacy}

Used a private room/screen for examination

Ensured nobody present other than medical team

\section{Confidentiality}

Did not share information without patient's consent

\section{Case management}

Gave patient the right to refuse treatment and change health care provider

Gave patient the opportunity to share in decision about treatment

Fully informed patient about cause(s) of illness

Fully informed patient about side-effects of treatment

Fully informed patient about cost of drugs

Made full examination of patient to reach diagnosis

Informed patient about follow-up visits

Total
100

100.0

100

100

94

90

67

89

89.0

100.0

100.0

94.0

93.0

90.0

67.0

3.0

97

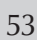

53.0

98.0

54.0

40.0

62.0

77.0
97.0

$100.0(0.0)$

0.0

0.0

82.6 (5.1)

6.0

7.0

74.5 (3.6)

$72.0(6.2)$

47.0

2.0

46.0

60.0

38.0

23.0

${ }^{a}$ Resident was considered compliant if he/she practised any of the 3 items of informed consent. $I Q R=$ interquartile range. 
two-thirds (67.0\%) were satisfied with the doctor's practice in obtaining an informed consent and $62.0 \%$ with having privacy during medical consultation. Only 49.0\% were satisfied with the doctor's practice of confidentiality. Just over half (52.0\%) claimed that they were satisfied with the doctor's way of communicating with them (Table 4).

\section{Patients' views of physicians' performance}

Of the patients $61.0 \%$ claimed that the physician discussed the causes of their illness, $37.0 \%$ complications of the disease, $60.0 \%$ treatment modality and $68.0 \%$ drugs and their possible side-effects. Only $42.0 \%$ were informed about the cost of treatment (Table 4).

Patients were significantly more likely to be satisfied with their ethical treatment if theywere aged $<20$ years $(P=0.017)$, of lower educational level $(P=0.003)$ and receiving preventive or rehabilitative care $(P=0.004)$ (Table 5). No significant differences were observed as regards the satisfaction of patients according to their $\operatorname{sex}(P=0.091)$, marital status $(P=0.395)$ or residence $(P=0.072)$. Significant differences were also observed as regards frequency of visits; patients attending $2+$ times were more likely to be dissatisfied $(83.7 \%)$ than those on the first visit $(28.1 \%)(P=0.002)$.

\section{Discussion}

In order to construct an effective ethics teaching curriculum for physician residents, the first step is to determine their current basic knowledge, perceptions and practices related to ethical issues and patients' rights. Ethical problems were common among physician residents in our study. The majority of residents (98.0\%) encountered ethical issues during their practice and $37.0 \%$ of them claimed that they faced them on a daily basis. This indicates the importance of preparing residents to deal with ethical dilemmas and providing them with guidance, support and supervision. Only 33.0\% of respondents preferred to consult their immediate supervisor about ethical issues and senior staff, and the head of the department was less frequently consulted. This finding is consistent with the commonly preferred option to settle the matter at the department level rather than taking it to the higher levels [4]. The end result will be that senior staff, who should act as mentors, will not be aware of ethical problems facing their junior staff, either because they have no time or due to administrative and communication barriers. Similar results were reported by Nakao et al. in Japan [5]. Our results showed that senior staff in Alexandria need to be more involved in the ethical problems that do arise and need to be prepared for guidance and handling of ethical problems.

It is interesting to note that few respondents (18.0\%) had obtained their knowledge of ethics from their medical education and $40.6 \%$ had learned about medical ethics from their own experience at work. This shows that the curricular training regarding ethics is either inadequate or ineffective. Also, if residents feel that their main source of knowledge of health care ethics is during experience at work, job experience should be used to reinforce ethical knowledge and practice.

Ethics committees are the most prominent formal institutional mechanism for considering and resolving ethical dilemmas in medicine. Despite that, hospital ethics committees are largely untested, unproven and unknown entities [6]. The present study indicated that the majority of physicians acknowledged the presence of an ethics committee in the faculty. Despite this, only a few of them stated that they approached the committee for advice. Awareness about the ethical committee in this study disagrees with another study regarding physicians' perceptions of a hospital ethics

\begin{tabular}{|c|c|c|c|c|}
\hline \multirow[t]{2}{*}{ Satisfaction item } & \multicolumn{2}{|c|}{ Satisfied } & \multicolumn{2}{|c|}{ Dissatisfied } \\
\hline & No. & $\%$ & No. & $\%$ \\
\hline \multicolumn{5}{|l|}{ Physician's practices in general } \\
\hline Manner in communicating & 52 & 52.0 & 48 & 48.0 \\
\hline Ensuring informed consent & 67 & 67.0 & 33 & 33.0 \\
\hline Ensuring privacy & 62 & 62.0 & 38 & 38.0 \\
\hline Ensuring confidentiality & 49 & 49.0 & 51 & 51.0 \\
\hline \multicolumn{5}{|c|}{ Physician's practices in informing and discussing } \\
\hline Causes of illness & 61 & 61.0 & 39 & 39.0 \\
\hline Complications of illness & 37 & 37.0 & 63 & 63.0 \\
\hline Treatment modalities & 60 & 60.0 & 40 & 40.0 \\
\hline Drugs and its possible side effects & 68 & 68.0 & 32 & 32.0 \\
\hline Cost of treatment & 42 & 42.0 & 58 & 58.0 \\
\hline
\end{tabular}

The median (interquartile range) was $63.9 \%$ (7.3). 


\begin{tabular}{|c|c|c|c|c|c|c|c|}
\hline \multirow[t]{2}{*}{ Variable } & \multirow[t]{2}{*}{$\begin{array}{c}\text { Total } \\
(n=100)\end{array}$} & \multicolumn{2}{|c|}{$\begin{array}{l}\text { Satisfied } \\
(n=48)\end{array}$} & \multicolumn{2}{|c|}{$\begin{array}{l}\text { Dissatisfied } \\
\quad(n=52)\end{array}$} & \multirow[t]{2}{*}{$x^{2}$} & \multirow[t]{2}{*}{$P$-value } \\
\hline & & No. & $\%$ & No. & $\%$ & & \\
\hline \multicolumn{8}{|l|}{ Age group (years) } \\
\hline$<20$ & 22 & 15 & 68.2 & 7 & 31.8 & \multirow{3}{*}{6.72} & \multirow{3}{*}{0.017} \\
\hline $20-<40$ & 35 & 17 & 48.6 & 18 & 51.4 & & \\
\hline $40+$ & 43 & 16 & 27.2 & 27 & 62.8 & & \\
\hline \multicolumn{8}{|l|}{ Sex } \\
\hline Male & 56 & 34 & 60.7 & 22 & 39.3 & \multirow{2}{*}{4.34} & \multirow{2}{*}{0.091} \\
\hline Female & 44 & 14 & 31.8 & 30 & 68.2 & & \\
\hline \multicolumn{8}{|l|}{ Marital status } \\
\hline Married & 48 & 28 & 58.3 & 20 & 41.7 & \multirow{2}{*}{0.96} & \multirow{2}{*}{0.395} \\
\hline Unmarried & 52 & 20 & 38.5 & 32 & 61.5 & & \\
\hline \multicolumn{8}{|l|}{ Education level } \\
\hline Secondary education or higher & 60 & 12 & 20.0 & 48 & 80.0 & & \multirow{2}{*}{$0.003^{\mathrm{a}}$} \\
\hline Less than secondary education/no formal education & 40 & 36 & 90.0 & 4 & 10.0 & & \\
\hline \multicolumn{8}{|l|}{ Residence } \\
\hline Urban & 47 & 17 & 36.2 & 30 & 63.8 & \multirow{2}{*}{4.77} & \multirow{2}{*}{0.072} \\
\hline Rural & 53 & 31 & 58.5 & 22 & 41.5 & & \\
\hline \multicolumn{8}{|l|}{ Type of care } \\
\hline Preventive & 10 & 9 & 90.0 & 1 & 10.0 & \multirow{3}{*}{$6.93^{b}$} & \multirow{3}{*}{0.004} \\
\hline Curative & 81 & 31 & 38.3 & 50 & 61.7 & & \\
\hline Rehabilitative & 9 & 8 & 88.9 & 1 & 11.1 & & \\
\hline \multicolumn{8}{|l|}{ Frequency of visits } \\
\hline First & 57 & 41 & 71.9 & 16 & 28.1 & \multirow{2}{*}{8.73} & \multirow{2}{*}{0.002} \\
\hline Second or more & 43 & 7 & 16.3 & 36 & 83.7 & & \\
\hline
\end{tabular}

${ }^{a}$ Fisher exact test; ${ }^{b}$ Monte Carlo test.

committee from the United States, in which large number of residents expressed dismay at the "invisibility" of the ethics committee [7]. Of our residents, $29.9 \%$ were dissatisfied with the role played by the present committee. Therefore, the role of the medical ethics committee in University of Alexandria hospitals should be strengthened to include involvement not only in research but also in education and advice about ethical issues.

The present study revealed that only $48.0 \%$ of physician residents were compliant with all the principles of ethics. Their levels of knowledge and perceptions were also lower than expected. Poor compliance might therefore be attributed to unsatisfactory levels of knowledge and perceptions about the subject, or it may be a reflection of the relatively high non-response rate to the questionnaire.

While a majority of our residents were aware of the common ethical issues and patient's rights, they had unsatisfactory levels of knowledge about certain ethical issues. This result suggests that medical ethics education in Alexandria should be strengthened in topics where knowledge levels were low. Medical education should also address changing attitudes and perceptions of residents. Previous research suggested that positive attitudes of residents toward ethics preparation improved beneficial outcomes of educational innovations [8]. Such findings support the belief that assessing trainees' attitudes, views and preferences is important in developing curricular approaches attuned to their concerns and experiences [9]. This information may help in the creation of curricular content and methods that are more acceptable to trainees $[10,11]$. In accordance, we found that the majority of residents disagreed with several statements related to physician-patient relationships. However, the strong negative perceptions of the residents about certain issues may reflect differences in the intensity of training. In a study on attitudes towards patient autonomy, residents in the United Kingdom showed a lower commitment to patient autonomy than did any of the United States groups [12]. The fact that $42.2 \%$ of residents in our study did not feel that the patient's wishes should be adhered to at all times shows the lack of knowledge about the fundamental principles of medical ethics. 
Critical steps toward improving the safety of the health care system include ensuring that the system is aware of its errors so that effective remedies can be applied, and enhancing the trustworthiness of the health care system for patients by disclosing errors that are meaningful to them [13]. In Fein et al.'s study all residents believed that errors should be disclosed. Important influences on whether disclosure would occur fell into 4 categories: provider, patient, error and institutional culture factors [14]. The present study addressed some of the above-mentioned factors. The majority of residents agreed that fear of malpractice was the main reason for non-disclosure of medical errors, while patients' forgiveness was another important motivator for disclosure. Further qualitative research is needed to apply the previous grounded model of error disclosure in order to delineate areas for interventions to increase disclosure as a step toward improving patient safety.

The present work described residents' perceptions abouthow physicians should behave towards one another. The obligation to report incompetence, impairment or misconduct of one's colleagues is emphasized in codes of medical ethics [15], but the majority of our respondents did not approve of reporting it. However, the application of this principle is not easy. A physician may be reluctant to report a colleague's misbehaviour because of friendship or sympathy or for fear of hostility on the part of the accused and possibly other colleagues [16].

Our observations of the actual practice of medical ethics by the residents showed that the majority of residents showed respect towards their patients. This is widely regarded as the most important principle of medical ethics [17]. The burden of patients at outpatient clinics of public hospitals in Egypt often makes it impossible for the doctors to follow the full protocol of privacy and patients' problems are often discussed in front of all present in the room. Such a practice may prevent the patient from revealing his/her complete history and symptoms [18]. A study from a public hospital in Karachi reported that the number of patients complaining of lack of privacy was greater than in more developed countries [19]. Nevertheless, the present work showed that privacy was mostly ensured during consultations. Similarly, the principle of confidentiality (information privacy) was also adequately practised. This was in accordance with a study in Canada that showed many family physicians fully understood their obligations towards patient confidentiality [20].

On the other hand, adherence to case management ethical principles in medical practice was inadequate in $\mathrm{Al}$ exandria teaching hospitals. One of reasons behind such a practice is that the cultural trends in Egypt still tend to accept the paternalistic model of medical care. This is in line with the Arab culture as a whole, where decision-making is often left purely to the doctors or other family members of the patient. A study from Karachi in Pakistan reflect similar practices, in which patients are willing to accept what doctors choose for them, while doctors are satisfied with their role as decision-makers [21]. While the situation in the US was not much different until the 1960s [22], current medical practice attaches great importance to the concepts of informed consent and shared decision-making. This differs substantially from the situation in Alexandria [23] and experts have called it a "cultural artefact", in that reliance on this concept is not universal [24]. Even in the US, there is often a clash between these ethical standards and the moral intuitions of many physicians [25].

It is noteworthy that there were other reasons for inadequate ethical practices in our setting. Although innovative ethical curricula have been shown to improve the confidence and practices of doctors with regards to medical ethics [26], medical education in Alexandria does not include bioethics training as a major component of the medical curriculum [27]. Lack of applied ethics training has also been noted in other countries such as Germany [28] and even the US, which has always championed the cause of bioethics [29]. The lack of education in ethics means that trainees can only learn from the practices of their consultants, most of whom belong to the era when a paternalistic approach towards patients was in vogue. This leads to a vicious cycle where every subsequent generation of doctors believes in paternalism. Even doctors who favour practices such as informed consent often abandon these practices in the belief that most of their patients are uneducated and would not be able to decide what is best for them. It is true, though, that patients often do not want to take decisions and allow doctors to decide for them. Furthermore, the lack of accountability and legal recourse means that doctors who do not respect patient ethics are never taken to task in Egypt [23].

The present work compared whether the patients' satisfaction and views of these ethical practices matched correctly with the observed assessment of residents' performance. Less than half of patients were satisfied with their physicians. In some instances, patients' were satisfied even when the physician's performance was judged to be unethical by the investigator. This finding can be explained by patients' misunderstandings of their ethical rights [30]. Public health programmes are needed to make patients aware of their legal rights to informed consent, confidentiality and privacy. The discordance observed may be related to characteristics of these patients as the study indicated that dissatisfied patients were those who were older, of higher education, obtained curative care and made frequent visits. Patients can under- or overestimate their ethical rights and hence their opinion may not necessarily be in line with current standards [1]. In other instances, 
patients' views about the physician's performance were similar to what was actually observed. For example dissatisfaction with instructions related to treatment reflects a distrust of doctors. Education needs to be directed at helping doctors gain the trust of patients [31].

Significant sex differences were observed between residents in the practice of medical ethics, with women being more compliant with ethical practices than men. This pattern replicates previous work [32]. Reasons for sex differences in adherence to ethical practices, and how these differences may influence patient care, remain uncertain [33]. Moazam proposed that women tend to adhere more to standards of morality and that their ideas of "goodness" depend on pleasing and helping others [34]. These results are an invitation for further study. Residents in psychiatry and paediatrics were more likely to comply with medical ethics standards than those in other departments. The practice of psychiatry and that of paediatrics, perhaps more than other medical specialties, place a heavy emphasis on dealing with people who may not always feel the need for expert assistance or may not be competent to understand their own needs. Ethics training demands careful attention to this particular challenge [35].

The present survey had some limitations. It relied on self-reported knowledge and perceptions and it involved a sample only of residents at a single teaching institution. This limits the generalization of results to other settings. The low response rate to the questionnaire may also have created a sampling bias. Nevertheless, the study highlights the need to identify physician residents who have unsatisfactory levels of knowledge, perceptions and practice towards ethical issues, to devise means to sensitize them to these issues and to train them appropriately.

\section{References}

1. Muaz F. Family, patient and physician in medical decision making. Hastings Center Report, 2000, 6:28-37.

2. McCullough LB, Chervenak FA. Informed consent. Clinics in Perinatology, 2007, 34:275-285i.

3. Mohamed AM, Ghanem MA, Kassem AA. Problems and perceived needs for medical ethics education of resident physicians in Alexandria teaching hospitals, Egypt. Eastern Mediterranean Health Journal, 2012, 18(8):827-835.

4. Mallardi V. Le origini del consenso informato [The origin of informed consent]. Acta Otorhinolaryngologia Italica, 2005, 25:312-327.

5. Nakao HX, Chishaki A, Obayashi M. Awareness of ethical issues by nursing professionals at a general local hospital in Japan. Fukuoka Igaku Zasshi, 2008, 99:175-183.

6. Denham MJ, Foster A, Tyrrell DA. Work of a district ethical committee. British Medical Journal, 1979, 2:1042-1045.

7. Hern HG Jr. Ethics and human values committee survey: (AMI Denver Hospitals: Saint Luke's, Presbyterian Denver, Presbyterian Aurora: Summer 1989). A study of physician attitudes and perceptions of a hospital ethics committee. HEC Forum, 1990, 2:105-125.

8. Perkins HS, Geppert CM, Hazuda HP. Challenges in teaching ethics in medical schools. American Journal of the Medical Sciences, 2000, 319:273-278.

9. Lazarus $\mathrm{CJ}$ et al. The program for professional values and ethics in medical education. Teaching and Learning in Medicine, 2000, 12:208-211.

10. Christakis DA, Feudtner C. Ethics in a short white coat: the ethical dilemmas that medical students confront. Academic Medicine, 1993, 68:249-254

11. Hébert PC, Meslin EM, Dunn EV. Measuring the ethical sensiE tivity of medical students: a study at the University of Toronto. Journal of Medical Ethics, 1992, 18:142-147.

12. Fulford KW, Yates A, Hope T. Ethics and the GMC core curriculum: a survey of resources in UK medical schools. Journal of Medical Ethics, 1997, 23:82-87.

13. Boothman RC et al. A better approach to medical malpractice claims? The University of Michigan experience. Journal of Health and Life Sciences Law, 2009, 2:125-159.
14. Fein $\mathrm{S}$ et al. A conceptual model for disclosure of medical errors. Advances in Patient Safety, 2005, 2:135-146.

15. Williams JR. Medical ethics manual, 2nd ed. Ferney-Voltaire Cedex, France, World Medical Association, 2009.

16. Del Carmen MG, Joffe S. Informed consent for medical treatment and research: a review. Oncologist, 2005, 10:636-641.

17. Beauchamp TL, Childress JF. Principles of biomedical ethics. New York, Oxford University Press, 2001:174-175.

18. Moskop JC et al. From Hippocrates to HIPAA: privacy and confidentiality in emergency medicine-part I: conceptual, moral, and legal foundations. Annals of Emergency Medicine, 2005, 45:53-59.

19. Shiraz B et al. Medical ethics in surgical wards: knowledge, attitude and practice of surgical team members in Karachi. Indian Journal of Medical Ethics, 2005, 2:94-96.

20. Geiderman JM, Moskop JC, Derse AR. Privacy and confis dentiality in emergency medicine: obligations and challenges. Emergency Medicine Clinics of North America, 2006, 24:633-656.

21. Jafarey A. Informed consent: views from Karachi. Eastern Mediterranean Health Journal, 2006, 12(Suppl. 1):S50-S55.

22. Oken D. What to tell cancer patients. A study of medical attitudes. Journal of the American Medical Association, 1961, 175:1120-1128.

23. Ali WF. Patient's consent to treatment with reference to the development of medical ethics in Alexandria teaching hospitals. Wiadomosci Lekarskie, 2007, 60:198-200.

24. Ruhnke GW et al. Ethical decision making and patient autonomy: a comparison of physicians and patients in Japan and the United States. Chest, 2000, 118:1172-1182.

25. Boisaubin EV. Observations of physician, patient and family perceptions of informed consent in Houston, Texas. Journal of Medicine and Philosophy, 2004, 29:225-236.

26. Mahmoud K. Informed consent and medical ethics. Annals of King Edward Medical College, 2005, 11:247-249.

27. Ali WF. Patient's consent to treatment with reference to the development of medical ethics in Alexandria teaching hospitals. Wiadomosci Lekarskie, 2007, 60:198-200. 
28. Moehring B, Schildmann J, Vollmann J. End-of-life decisions: a comparative survey on (teaching) experiences, views, and ethico-legal knowledge of final-year medical students in Germany and France. Journal of Palliative Medicine, 2011, 14(11):1206-1210.

29. Mattick K, Bligh J. Undergraduate ethics teaching: revisiting the Consensus Statement. Medical Education, 2006, 40:329-332

30. Amin FM et al. An audit of information provided during Preoperative informed consent. Pakistan Journal of Medical Sciences, 2006, 22:10-13.

31. Imam SZ et al. Patients' satisfaction and opinions of their experiences during admission in a tertiary care hospital in Pakistan-a cross sectional study. BMC Health Services Research, 2007, 7:161.
32. Cleary PD et al. Patients evaluate their hospital care: a national survey. Health Affairs (Project Hope), 1991, 10:254-267.

33. Jafarey AM, Farooqui A. Informed consent in the Pakistani milieu: the physician's perspective. Journal of Medical Ethics, 2005, 31:93-96.

34. Moazam F. Family, patient and physician in medical decision making: a Pakistani perspective. Hastings Center Report, 2000, 6:28-37.

35. International ethical guidelines for biomedical research involving human subjects. Geneva, Council of International Organizations for Medical Science, 2002.

\section{9th Global Summit of National Ethics Committees}

An increasing number of countries have created national ethics committees (NECs) to provide advice about ethical issues related to health to their executive and legislative branches as well as to the general public. The Global Summit of the National Ethics Committees is a biennial world meeting that has been held since 1996 and which:

- Provides a unique platform for exchange of information about on-going work of the NECs.

- Gives the opportunity for open debate, focusing on specific issues such as the protection of human participants in health research, stem cell research, end of life choices, etc.

- Facilitates access to working documents prepared and circulated previous to the meeting.

- Contributes to update information regarding the status and functions of national bodies.

The 9th Global Summit of National Ethics Committees is being hosted by Tunisia in Carthage from 26 to 28 September 2012. This is the first time the Summit will take place in Africa. Further information about the Summit is available at: http://www.9gsnec.tunisia2012.rns.tn/congre_en/ 